\title{
FE DE ERRATA
}

HALPIN P, T STRUB, W PETERSON \& T BAUMGARTNER (2004) An overview of interactions among oceanography, marine ecosystems, climatic and human disruptions along the eastern margins of the Pacific Ocean. Revista Chilena de Historia Natural 77: 371-409.

Producto de un cambio en los agradecimientos solicitado por los autores, la versión correcta de los Agradecimientos es la siguiente:

Upon a change request by the authors, the correct text of Acknowledgments is as it follows:

\section{ACKNOWLEDGMENTS}

The authors wish to thank Bruce Menge, Jane Lubchenco and the members of their laboratory for their input on the manuscript. Writing of this manuscript was supported in part by the Andrew J. Mellon Foundation, the David and Lucile Packard Foundation and the U.S. GLOBEC program. This is contribution number 28 of the Partnership for Interdisciplinary Studies of the Coastal Oceans (PISCO): A LongTerm Ecological Consortium, funded by the David and Lucile Packard Foundation. This is also contribution number 499 of the US GLOBEC program, funded jointly by the National Science Foundation and the National Oceanic and Atmospheric Administration. Finally, this paper represents a contribution to the scientific agenda of the Eastern Pacific Consortium (EPCOR) of the InterAmerican Institute for Global Change Research (IAI). 